\title{
EDUCAÇÃO - DA PAIDÉIA DE W. JAEGER À MODERNIDADE LÍQUIDA DE Z. BAUMAN
}

\author{
Virgínia da Silva Ferreira ${ }^{1}$ \\ http://orcid.org/0000-0001-6706-156X
}

\author{
Vera Rudge Werneck ${ }^{2}$ \\ http://orcid.org/0000-0002-3545-2870
}

RESUMO: Com a passagem da modernidade para a modernidade líquida, a sociedade se viu imersa em inúmeras crises de paradigmas que se apresentam em todos os campos: social, cultural, econômico, afetivo, educacional, religioso, político, entre outros. Mudou a noção de família, nação, religião, consumo, educação. Ou seja, mudou a hierarquia de valores, a forma de estar no mundo, de perceber, pensar e agir sobre ele. Este trabalho tem o objetivo de pensar a educação na contemporaneidade, uma época que Zygmunt Bauman nomeia de modernidade líquida. Para caracterizá-la, tomaremos como base o pensamento de Z. Bauman; para pensar a educação, recorreremos ao filósofo alemão Werner Jaeger, em sua obra Paidéia: a formação do homem grego; por fim,o conceito de educação que norteará este artigo é o proposto por Vera Werneck, em sua obra Educação e Sensibilidade: um estudo sobre a teoria dos valores.

PALAVRAS-CHAVE: educação, modernidade líquida, Paidéia.

\section{EDUCATION - FROM W. JAEGER'S PAIDEIA TO Z. BAUMAN'S LIQUID MODERNITY}

ABSTRACT: With the shift from modernity to liquid modernity, society has been immersed in innumerable crises of paradigms that are present in all fields: social, cultural, economic, affective, educational, religious, political, among others. The notion of family, nation, religion, consumption and education has changed. That means that the

\footnotetext{
${ }^{1}$ Doutoranda em Educação - Universidade Católica de Petrópolis - UCP. Petrópolis - RJ - Brasil. virferreira16@gmail.com

${ }^{2}$ Doutora em Filosofia - Profa. Programa de Pós-Graduação em Educação da Universidade Católica de Petrópolis - UCP. Petrópolis - RJ - Brasil.vera.werneck@ucp.br 
hierarchy of values, the ways of being in the world, perceiving it, contemplating it and acting on it have changed. This paper aims to think of education in the contemporary world, an era that Zygmunt Bauman calls liquid modernity. In order to characterize it, we will take as a base the thought of Z. Bauman; to reflect on education, we will resort to the German philosopher Werner Jaeger, in his work Paideia: the formation of the Greek man; finally, the concept of education that will guide this paper is the one proposed by Vera Werneck, in her work Educação e Sensibilidade: um estudo sobre a teoria dos valores (Education and Sensitivity: a study on the theory of values).

KEYWORDS: education, liquid modernity, Paideia.

\section{EDUCACIÓN - DE LA PAIDEIA DE W. JAEGER A LA MODERNIDAD LIQUIDA DE Z. BAUMAN}

RESUMEN: Con el paso de la modernidad a la modernidad líquida, la sociedad se ha encontrado inmersa en innumerables crisis de paradigmas que se presentan en todos los campos: social, cultural, económico, afectivo, educativo, religioso, político, entre otros. Se ha cambiado la noción de familia, nación, religión, consumo, educación. Es decir, se ha cambiado la jerarquía de valores, la forma de estar en el mundo, percibirlo, pensarlo y actuar en consecuencia. Este trabajo tiene como objetivo pensar en la educación en los tiempos contemporáneos, una era que Zygmunt Bauman Ilama modernidad líquida. Para caracterizarla, tomaremos como base el pensamiento de $Z$. Bauman; y para pensar en la educación, el filósofo alemán Werner Jaeger, en su obra Paideia: Los ideales de la cultura griega, y el concepto de educación que guiará este artículo, es la propuesta por Vera Werneck, en su trabajo: Educação e Sensibilidade: um estudo sobre a teoria dos valores (Educación y Sensibilidad: un estudio sobre la teoría de los valores).

PALABRAS CLAVE: educación, modernidad líquida, Paideia.

\section{Introdução}

De acordo com Werneck (2013, p. 37),"vai-se entender aqui a educação como um processo de reconhecimento, busca, apreensão e hierarquização de valores de modo próprio e adequado para promover a humanização do homem enquanto pessoa e enquanto personalidade". Entretanto, como dizem 
Moreira e Candau (2003, p. 159), "não há educação que não esteja imersa na cultura da humanidade e, particularmente, do momento histórico em que se situa".

A história da humanidade é permeada por diferentes sistemas de referências que influenciam tanto a forma de pensamento quanto a forma de se posicionar e agir no mundo. Na era primitiva, a referência eram os mitos. $\mathrm{Na}$ antiguidade, com Sócrates, Platão e Aristóteles, era o homem. De acordo com Jaeger,

A ideia de educação representava para ele, o homem grego, o sentido de todo esforço humano. Era a justificação última da comunidade e individualidade humanas. O conhecimento próprio, a inteligência clara do grego encontrava-se no topo do seu desenvolvimento (2003, p.7).

Na idade média, prevalecia o monoteísmo universalista cristão, ou seja, Deus. Na modernidade sólida, predominam Deus, o homem e a ciência. Na modernidade líquida, prevalece o capitalismo, em outras palavras, o consumismo, que se traduz pelo consumo não reflexivo, sendo este, sobretudo, o verdadeiro e único sentido da existência humana. Como diz Badiou, "a única universalidade que o mundo atual aceita é a do mercado e da moeda. Fora disto, cada um está encerrado em sua própria tribo[...]" (apud DA POIN, 2001, p.17-18).

Bauman (2010), no que tange às mudanças ocorridas no cerne da sociedade, com a passagem da modernidade sólida para a modernidade líquida, expõe algumas questões que são,ao mesmo tempo, elementares e essenciais, produtos e origens do capitalismo. Entre as questões, temos: a fluidez dos laços sociais, as explicações e sentidos contemporâneos, e as novas interpretações sociais, políticas, econômicas e culturais, originadas na transição dos modos de produção e de exploração capitalista.

Estamos diante de um cenário de fragmentação no qual nenhuma esfera está incólume ou foi poupada. Desta forma, as esferas social, econômica, política, cultural, afetiva, educacional, entre outras, estão sob a égide (ou tirania) do sistema de referência da modernidade líquida, que, pela fragmentação que lhe é própria, origina a ambivalência que se mostra como a inabilidade de se viver sob alicerce estáveis e duradouros. De acordo com Paul Valéry:

Interrupção, incoerência, surpresa são as condições comuns de nossa vida. Elas se tornaram mesmo necessidades reais para muitas pessoas, cujas mentes deixaram de ser alimentadas 
[...] por outra coisa que não mudanças repentinas e estímulos constantemente renovados [...]. Não podemos mais tolerar o que dura. Não sabemos mais fazer com que o tédio dê frutos (apud BAUMAN, 2001, p. 7).

A modernidade líquida imprimiu mudanças profundas na forma como o homem se relaciona com o consumo e, consequentemente, consigo mesmo, com o mundo e com todos os elementos que, por natureza, estão presentes nas sociedades. Assim sendo, a educação não poderia escapar desse turbilhão de ambivalência e interesses que a atingiu impiedosamente.

Atribuir importância às diversas informações e, sobretudo, atribuir maior importância a umas que as outras talvez seja a tarefa mais desconcertante e a decisão mais difícil. $\mathrm{O}$ único critério prático que se pode adotar é a pertinência momentânea, mas ela também muda de um momento para outro, e as informações assimiladas perdem significado assim que são utilizadas. Como outros produtos no mercado, elas são destinadas ao instantâneo, imediato e único (BAUMAN, 2010, p. 59).

Ora, se vivemos na era da volatilidade, do consumismo, do utilitarismo, das rápidas mudanças, das identidades passageiras, enfim, da fluidez, surge a seguinte questão: como pensar a educação - uma atividade resultante da seleção que visa transformar as pessoas naquilo que elas devem ser - numa era na qual as identidades são passageiras; numa era na qual o que ontem era verdade, em pouquíssimo tempo, já não o é mais; numa era na qual a única certeza é a incerteza?

A educação participa na vida e no crescimento da sociedade, tanto no seu destino exterior como na sua estruturação interna e desenvolvimento espiritual; e, uma vez que o desenvolvimento social depende da consciência dos valores que regem a vida humana, a história da educação está essencialmente condicionada pela transformação dos valores válidos para cada sociedade. À estabilidade das normas válidas corresponde a solidez dos fundamentos da educação. Da dissolução e destruição das normas advêm a debilidade, a falta de segurança e até a impossibilidade absoluta de qualquer ação educativa (JAEGER, 2003, p.4).

Cabe ressaltar que, neste texto, não temos a menor pretensão de esgotar o tema nem de reivindicar todo e qualquer tipo de exclusividade ou inovação quanto à forma como as ideias e teorias são aqui relacionadas e 
dispostas. Somente temos o objetivo de pensar o propósito da educação na modernidade líquida.

\section{Paidéia de Werner Jaeger}

Todo povo que atinge um certo grau de desenvolvimento sente-se naturalmente inclinado à prática da educação. Ela é o princípio por meio do qual a comunidade humana conserva e transmite a sua peculiaridade física e espiritual [...]. Uma educação consciente pode até mudar a natureza física do Homem e suas qualidades, elevando-lhe a um nível superior. Mas o espírito humano conduz progressivamente à descoberta de si próprio e cria, pelo conhecimento do mundo exterior e interior, formas melhores de existência humana (JAEGER, 2003, p. 3).

A palavra Paidéia não se permite elevar a um único sentido, a uma determinação fechada, pois é resistente às formulações conceituais abstratas. Jaeger (2003) assemelha o conceito de Paidéia a outros conceitos difíceis de definir, como filosofia e cultura. Porém, assegura que o termo Paidéia é o que define exatamente o que significa a história, os ideais e o percurso da educação grega.

O surgimento da Paidéia se dá com base na universalidade do bem, do justo, do belo, e é assim que se desenvolvem os ideais de formação do homem grego. Saliento o fato de que,a priori, o surgimento da Paidéia reflete unicamente a preocupação com a formação dos meninos, mas, a posteriori, por meio do desenvolvimento de seus princípios, a Paidéia adquiriu particularidade histórica e singularidade ímpar, as quais, junto à influência da cultura grega,iriam influenciar todo o ocidente. A noção de formação/educação no contexto da sociedade grega diz respeito, originalmente, a uma opção, uma forma de ver e estar no mundo.

A filosofia, enquanto caminho primeiro para a formação, não representava apenas adquirir conhecimento ou, ainda, aprender a fazer algo; o ensino sempre fora voltado à totalidade e com alcances à coletividade. Jaeger afirma que Sócrates: "era o grande conhecedor de homens, cujas perguntas certeiras serviam de pedra de toque para descobrir todos os talentos e todas as forças latentes, e a quem iam pedir conselho, para educação dos filhos, os cidadãos mais respeitados" (2003, p. 522).

Hans-Georg Gadamer (1900-2002), um dos mais importantes filósofos do século XX, assegura que um retorno aos gregos é, para todos nós, ocidentais, uma espécie de encontro com nós mesmos (2000a; 2000b). Ele se refere à he- 
rança grega no modo como formularam a filosofia, diferente do modo como a aplicamos na atualidade, mas de forma mais ampla. A magnitude da filosofia grega diz respeito às inquietações compreendidas pela dimensão teórica, e, com isso, podemos incluir também a totalidade científica, a qual, indubitavelmente, foi responsável pelo impulso da civilização moderna (GADAMER, 2000a). Assim se justifica esse encontro entre nós enquanto modernos e, ao mesmo tempo, gregos, quando nos julgamos processo que resulta da influência grega antiga.

A partir de um recorte histórico, apontaremos os ideais propostos por Sócrates (469-399 a.C.), em sua maioria, narrados por Platão (427-347 a.C.). "Sócrates é o mais espantoso fenômeno pedagógico da história do ocidente" (JAEGER, 2003, p. 512). Senhor de uma espécie de "não-saber", Sócrates era visto pelos seus concidadãos como ser sábio e também irônico. Hadot (1999), quando trata da filosofia antiga, narra esse "não-saber" socrático e abeira-sedas estratégias de educação, ou, ainda, de formação, propostas por Sócrates. De maneira "desinteressada", Sócrates se aproximava de seus colocutores nas ruas, nas praças, em suas casas e, entre outros lugares, os interpelava sobre seus ofícios, especialidades, profissões e opiniões gerais. Sua estratégia sempre fora o diálogo, e,no decorrer deste, fazia com que seus colocutores fossem se autodescobrindo, desconstruindo algumas certezas e construindo outras.

Sócrates, ao questionar seus colocutores, fazia com que as certezas, embasadas num conhecimento antiquíssimo, ficassem débeis e fossem simultaneamente reformuladas. Ele proporcionava ao seu colocutor a busca pela verdade, o próprio colocutor alcançava e concebia -paria seu conhecimento. A precedência em Sócrates é fazer com que o colocutor, o sujeito do diálogo, busque e encontre em si suas próprias verdades.

Podemos acrescentar à figura de Sócrates a colocação feita por Jaeger (2003). Para o autor, Sócrates concebe o diálogo como apresentação primordial do pensar filosófico e percurso único capaz de nos levar ao entendimento e compreensão das nossas relações com os outros. Sem se apresentar como "senhor da verdade", Sócrates também é um aprendiz, ao passo que seu colocutor vai elaborando suas próprias certezas, suas próprias verdades. Neste ponto, partilhamos do entendimento gadameriano para alicerçar, de forma inerente, a práxis pedagógica fundamentada no diálogo vivo. "[...] creio que só se pode aprender através da conversação"(GADAMER, 2000b, p. 10). Nesse mesmo texto, Gadamer aponta para a perspectiva de que "educação é educar-se" e "formação é formar-se". Em outras palavras, é uma via de mão dupla.

A Paidéia socrática se apresenta como pesquisa e problematização, pois Sócrates se mantém em busca da libertação individual e do amadure- 
cimento intelectual de seus colocutores, que, por sua vez, abrigam em seu interior a voz do mestre e se fazem mestres de si mesmos (CAMBI, 1999). A abrangência pedagógica dessa prática da dialética socrática está sempre direcionada ao coletivo, ou seja, mesmo quando realizada de forma individual, é a universalidade que se manifesta como fundamento.

Hadot (1999), ao fazer referência à obra O Banquete, de Platão, diz que a postura de Sócrates, seu modo de ser e estar no mundo, mostra-nos que ele é o homem que busca acercar-se dos outros e fazer com que os outros se avizinhem dele, utilizando como elemento intermediador a procura da sabedoria. Os ideais e as atitudes de Sócrates ilustram com propriedade o que é o ser ético e político, ser este que apresenta ideais edificantes à sua época e à contemporaneidade.

[...] Sócrates é um cidadão simples, a quem todos conhecem. A sua ação passa quase despercebida; a conversa com ele agarra-se quase espontaneamente, e como sem querer, a qualquer tema de ocasião. Não se dedica ao ensino nem tem discípulos; assim o afirma, pelo menos. Só tem amigos, camaradas. A juventude sente-se fascinada pelo fio cortante daquele espírito, ao qual não há nada que resista (JAEGER, 2003, p. 523).

É evidente que, em Sócrates, pensamento e ação são inseparáveis; assim, a prática de encimar o real, as experiências e o dia a dia - de forma crítica, reflexiva, perseverante e inexaurível até o conceito - evidencia-se como princípio e razão para a retomada do liame entre filosofia e educação. Contanto que logremos ou retomemos essa abordagem da qual somos legatários, estaremos substancializando a conexão do diálogo ético, que se traduz no restabelecimento da "ética dialética de Platão, articulada no diálogo socrático" (FLICKINGER, 2010, p. 92).

A aproximação do diálogo vivo com as práticas pedagógicas só é viável caso nós, os educadores, incorporemos a postura socrática, substituindo o antagonismo e a dessemelhança - muitas vezes não manifesta -, que rege os processos de ensino e da aprendizagem. A concretização dessa postura socrática na atualidade não pode ser interpretada e entendida como um princípio ilógico e disparatado, mas,antes, deve ser interpretada e entendida como a possibilidade da unicidade e dos alcances coletivos.

Ser e estar no mundo de forma "ética dialética" articulada ao modo do "diálogo socrático" possibilita que novos caminhos se apresentem como exequíveis na formação-educação na atualidade. O pensar e o agir indissociá- 
veis e a dialética, na concepção em que estamos tratando essa perspectiva, não outorgariam o escoramento e a procura por verdades absolutas e certezas inabaláveis. $O$ diálogo por essa via não se mantém enquanto possibilidade única e definitiva para se afiançar um "saber verdadeiro", alcançar a "verdade única", ou se apropriar de certezas irrefutáveis.

O propósito maior do reaver dialógico é o de engendrar a nãoobjetividade científica moderna, de não escolhermos como certo e verdadeiro tão somente o que a ciência moderna institui como verdade. $O$ entendimento disso nos destina à revogação de uma práxis pedagógica totalmente excludente, não dialógica e não reflexiva, que limita e aliena a oportunidade de perceber e apreender o real com nitidez e propriedade.

[...] o conceito de decisivo para a história da paidéia (grifo do autor) é o conceito socrático do fim da vida (grifo do autor). Através dele, a missão de toda educação é banhada por uma luz nova: já não consiste no desenvolvimento de certas capacidades nem na transmissão de certos conhecimentos; pelo menos, agora isto só pode ser considerado um meio e uma fase no processo educacional. A verdadeira essência da educação é dar ao Homem condições para alcançar o fim autêntico da sua vida. Identifica-se com a aspiração socrática ao conhecimento do bem, com a phronesis (grifo do autor). E esta aspiração não se pode restringir aos poucos anos de uma chamada cultura superior. Só pode alcançar seu objetivo ao longo de toda vida do Homem [...]. Isto faz mudar o conceito de essência da Paidéia (grifo do autor). A cultura em sentido socrático converte-se na aspiração a uma ordenação filosófica consciente da vida, que se propõe cumprir o destino espiritual e moral do Homem. 0 Homem, assim concebido, nasceu para a paidéia (grifo do autor). Esta é o seu único patrimônio verdadeiro (JAEGER, 2003, p. 571).

\section{Modernidade líquida de Zygmunt Bauman}

Interrupção, incoerência, surpresa são as condições comuns de nossa vida. Elas se tornaram mesmo necessidades reais para muitas pessoas, cujas mentes deixaram de ser alimentadas.... por outra coisa que não mudanças repentinas e estímulos constantemente renovados. Não podemos mais tolerar o que dura. Não sabemos mais fazer com que o tédio dê frutos.

Assim, toda a questão se reduz a isto: pode a mente humana dominar o que a mente humana criou? (VALÉRY apud BAUMAN, 2001, p.7). 
Bauman (2001), ao falar da pós-modernidade, cria o termo modernidade líquida, título de seu livro publicado em 2001, na virada do século XXI. Explica que a fluidez é a qualidade dos líquidos e gases. Os fluidos se movem facilmente, escorrem, transbordam e "diferentemente dos sólidos, não são facilmente contidos - contornam certos obstáculos, dissolvem outros e invadem ou inundam seu caminho" (2001, p.8). Segue o autor afirmando que, além das características supracitadas, os fluidos ainda são associados à ideia de leveza. 'Associamos 'leveza' ou 'ausência de peso' à mobilidade e a inconstância" (2001, p.8). O autor segue dizendo que as metáforas "liquidez" e "fluidez" captam as características da natureza dessa nova modernidade, que podem ser resumidas em: emancipação, individualidade, tempo, espaço, liberdade, consumismo, descartabilidade, mudanças rápidas, volatilidade, incertezas, entre outras.

Abandonar os padrões muito rígidos, ser condescendente com a falta de critérios, satisfazer todos os gostos sem privilegiar nenhum deles, promover a inconsistência e a "flexibilidade" (nome politicamente correto da frouxidão de caráter) e exaltar a instabilidade e a incoerência, esta é, portanto, a estratégia justa (a única razoável?) hoje (BAUMAN, 2010, p.15).

As profundas mudanças ocorridas na sociedade têm uma íntima relação com o capitalismo; e não seria ilegítimo dizer que são decorrentes desse sistema, que tem como objeto central de preocupação a criação e manutenção do consumismo. "O consumismo chega quando o consumo assume o papel chave na sociedade[...]" (BAUMAN, 2008a, p.41). Desta forma, o consumismo é um atributo da sociedade, que é mantida em permanente insatisfação.

O sujeito se torna fruto e vítima daquilo que lhe é imposto e que o golpeia. Ele irá se definir, então, pelo real do corpo, da genética, dos psicofármacos, do sexo, da beleza, da velhice. Basta ver, por exemplo, a importância do dinheiro como bem central e da repetição mimética dos modelos propostos pela mídia, em que a publicidade controla o poder de decisão do indivíduo fazendo-o consumir o que a indústria precisa vender (DA POIN, 2001, p. 14).

De acordo com Bauman (2008a), as relações humanas são constituídas em consonância com o padrão e à semelhança das relações entre aqueles que consomem e os objetos por eles consumidos. Estas relações se fazem presentes em todas as esferas da sociedade, em todas as esferas do consumo - ideias, 
conhecimento, bens materiais, ideologias, identidades, entre outras - e sempre regidas pela volatilidade, utilidade imediata, publicidade e descartabilidade.

Segundo Silva, Mendes e Alves (2015), algumas diferenças entre a modernidade sólida e a modernidade líquida ficam claras nas obras de Bauman. Os laços familiares estão modificados. $O$ indivíduo forma várias famílias, rompendo, assim, com a ideia moderna das histórias de amor e com os laços sagrados da família. A sociedade de produção transformou-se em sociedade de consumo, e é justo a partir da mudança da relação do homem com o consumo que todas as demais mudanças aconteceram.

Deixamos de pensar a ideia moderna de comunidade, e a vida humana sofreu uma fragmentação. "Por isso mesmo essa forma de 'derreter os sólidos' deixava toda a complexa rede de relações sociais no ar - nu, desprotegido, desarmado e exposto, impotente para resistir às regras de ação e aos critérios de racionalidade" (BAUMAN, 2000/2001, SILVA; MENDES; ALVES, 2015, p. 252).

Segundo Bauman (apud PORCHEDDU, 2009) a aprendizagem e a pedagogia vêm, ao longo de seu curso histórico, superando desafios em suas estratégias e estruturas. Foram criadas para um mundo duradouro, em que a memória era um elemento precioso. Hoje, esse tipo de memória mostra seu potencial incapacitante e talvez até inútil. As redes eletrônicas e os servidores prometiam resolver os problemas de memorização e também do descarte do que fosse aparentemente inútil. Parecia atraente ter a possibilidade de armazenagem de informações fora do cérebro. $O$ problema é que essas redes e servidores não tinham um modo confiável para decidir quais seriam as memórias que permaneceriam armazenadas e quais deveriam ser descartadas.

Na vida moderna, durante o que Bauman (apud PORCHEDDU, 2009) denomina fase "sólida", deixava-se claro e fixo quais seriam os caminhos certos e errados, e, assim, os que decidiam por caminhos errados poderiam facilmente ser punidos. Os que eram obedientes, no entanto, eram recompensados. Desta forma, o "domínio" determinava e vigiava o cumprimento das obrigações e realinhava os desviantes. Na fase "líquida" (BAUMAN apud PORCHEDDU, 2009), quem quiser obter sucesso deve demonstrar curiosidade, comunicação e colocar a sua própria pessoa como valor único e insubstituível. Ou ainda, como diz Lipovetzky:

[...] a cultura pós-moderna é um vetor de aumento do individualismo; diversificando as possibilidades de escolha, liquidificando os pontos de referência, minando o sentido único dos valores superiores da modernidade [...]. Os desejos individualistas hoje em dia nos esclarecem mais do que os interesses de classes, a 
privatização é mais reveladora do que os relatórios de produção, o hedonismo e o psicologismo são mãos fecundos do que os programas e as formas de ações coletivas, ainda que sejam novas; o conceito de narcisismo tem por objetivo fazer eco a esta culminação da esfera privada (LIPOVETZKY, 2005, p.XXI-XXII).

A pedagogia está diante de desafios nessa reviravolta da história humana. Os educadores precisam aprender a difícil tarefa de educar o ser humano neste modelo de vida, em que a vida do indivíduo é dedicada à sobrevivência em condições frágeis, laços estendidos, realidade volátil e, por isso, necessitando sempre de novos inícios. Na modernidade líquida, o indivíduo precisa de uma série de competências e informações que deixam as anteriores para trás, em cada episódio dos projetos conduzidos em sua vida.

Os centros de ensino e aprendizagem são submetidos a uma pressão "desinstitucionalizante", ou seja, valorizam a flexibilidade antes presumida como lógica interna das disciplinas escolares. Ressalta Bauman (apud PORCHEDDU, 2009) que as pressões vêm tanto do governo, que pretende acompanhar o movimento volátil da economia mundial, quanto dos estudantes, capturados pela demanda do mercado de trabalho de natureza imprevisível.

$O$ deslocamento de ênfase do ensino à aprendizagem evidencia essa pressa. Também revelando essas pressões desinstitucionalizantes estão os processos de ensino-aprendizagem no que tange à sua privatização e individualização, substituindo a relação professor-aluno pela de fornecedor-cliente.

Para completar a versão popular e revista do cogito de Descartes, "Compro, logo sou...", deveria ser acrescentada "um sujeito". E à medida que o tempo gasto em compras se torna mais longo (fisicamente ou em pensamento, em carne e osso ou eletronicamente), multiplicam-se as oportunidades para se fazer esse acréscimo (BAUMAN, 2008a, p. 26-27).

Para Bauman (apud PORCHEDDU, 2009), este é o contexto social apresentado aos educadores na atualidade. As suas respostas e a eficácia das estratégias utilizadas para promover tais respostas são destinadas a permanecer por longo tempo como objeto crucial de estudo das ciências pedagógicas.

\section{Considerações finais}

Apesar de o texto abordar o tema da educação a partir das perspectivas da Paidéia de Jaeger, e da modernidade líquida de Bauman, são muitos 
os teóricos que pesquisaram e pesquisam sobre o tema. No entanto, nenhum conseguiu esgotá-lo, tanto por sua complexidade, quanto por sua inserção no movimento da história da humanidade e principalmente porque, tudo que esteja ligado de forma direta ou indireta à educação é e, talvez, sempre será, por um lado, um porvir e, por outro, um instrumento de poder, a serviço de alguém ou alguma coisa - sistema, Estado, classes dominantes etc.

Independentemente do conceito de educação construído e adotado, são inúmeros os fatores que interferem na práxis ou efetivação do modelo. Tais fatores incluem: o sistema de referências de uma dada época, neste caso, a modernidade líquida, nomenclatura proposta por Bauman para caracterizar a época em que vivemos, nas quais temos as mudanças rápidas, a utilidade e a não valorização da durabilidade dos conhecimentos e das coisas e, portanto, a descartabilidade; as condições de trabalho dos professores, entre inúmeros outros fatores que interferem na prática cotidiana do docente e, por conseguinte, na consecução do currículo. A educação não mais ocupa lugar privilegiado com o propósito de formar o homem em sua integralidade, como em épocas passadas, na Grécia, por exemplo.

A ideia de educação representava para ele, o homem grego, o sentido de todo esforço humano. Era a justificação última da comunidade e individualidade humanas. O conhecimento próprio, a inteligência clara do Grego encontrava-se no topo do seu desenvolvimento (JAEGER, 2003, p.7).

Na modernidade líquida, a trilogia composta por educação, pedagogia e currículo é volátil, submetida à imprevisibilidade das rápidas mudanças - produtos para serem consumidos, utilizados e, logo em seguida, descartados. Já na era moderna, período em que o mundo se mostrava duradouro e a educação era valorizada como instrumento de formação do homem em sua integralidade e como possibilidade de ascensão social, os paradigmas se revelavam de maneira diferente da vicissitude dessa trilogia. "A modernidade sólida era verdadeiramente a era dos princípios duradouros e concernia, sobretudo, aos princípios duráveis que eram conduzidos e vigiados com grande atenção" (BAUMAN, apud PORCHEDDU, 2009, p. 666).

Talvez não tenhamos ganhado grande coisa em afirmar que os gregos foram os criadores da ideia de cultura, num tempo cansado de cultura e em que se pode considerar como sobrecarga essa paternidade. Mas o que hoje denominamos cultura não passa de um produto deteriorado, derradeira metamorfose do 
conceito grego originário (JAEGER, 2003, p. 8).

Se a educação era sustentada sobre uma base sólida e, ainda, ela mesma sustentava a sociedade, hoje esse modo singular e sólido de conceber a educação se esgotou na volatilidade da modernidade líquida. Não há nem solidez nem certezas; não há nem um sistema de valores duradouros nem um sentimento de coletividade; não há nem objetos simbólicos nem narrativas que visem uma totalidade. De acordo com o sociólogo italiano Alberto Melucci, "estamos contaminados pela fragilidade da condição presente, que exige um alicerce firme onde não existe alicerce algum" (apud BAUMAN, 2013, p. 14).

Em contraponto, na Grécia antiga,

A educação participa na vida e no crescimento da sociedade, tanto no seu destino exterior como na sua estruturação interna e desenvolvimento espiritual; e, uma vez que o desenvolvimento social depende da consciência dos valores que regem a vida humana, a história da educação está essencialmente condicionada pela transformação dos valores válidos para cada sociedade. À estabilidade das normas válidas corresponde a solidez dos fundamentos da educação. Da dissolução e destruição das normas advém a debilidade, a falta de segurança e até a impossibilidade absoluta de qualquer ação educativa (JAEGER, 2003, p. 4).

Se vivemos numa era líquida, em que tudo é volátil e flui, como pensara educação nesta era? Que seleção fazer dos conteúdos, conhecimentos e valores, numa era de mudanças rápidas, em que o que era verdade ontem hoje já não mais o é? Quais comportamentos pretender de sujeitos que se apropriam de identidades passageiras? Como pensar no valor da educação numa era na qual o valor está submetido à utilidade? Ou seja, estamos falando de uma era na qual as coisas - a educação, o conhecimento, o currículo, as relações sociais, entre outras -não têm utilidade pelo seu valor, mas, sim, têm valor pela sua utilidade. Isso quer dizer que vivemos numa época em que tanto os sujeitos como as coisas não passam de meras mercadorias que devem ser consumidas e descartadas, isso porque são regidas pela lógica do mercado e da moeda.

Apesar da fluidez, da volatilidade, do imediatismo, do consumismo, das mudanças rápidas etc., esta é a era em que vivemos. De acordo com Jackson, "é uma história sobre nós, pessoas, sendo convencidas a gastar o dinheiro que não temos com coisas que não precisamos para dar a impressão de que elas irão perdurar às pessoas para quem não ligamos"(apud BAUMAN, 2017, p. 115). 
Dentro da perspectiva baumaniana de modernidade líquida, a educação talvez só tenha lugar se não tiver forma, como os líquidos não têm. Mas, será possível uma educação sem forma, ou será necessário inventar um novo instrumento, com um outro nome, para o que se chama de educação hoje?

De acordo com Werneck (2013), "[...] educação é o processo de reconhecimento, busca, apreensão e hierarquização dos valores de modo próprio e adequado para promover a humanização do homem enquanto pessoa e enquanto personalidade [...]"(p. 37). Ainda,

Ao mesmo tempo em que é "pessoa", cada ser humano tem uma "personalidade" singular e única com características individualizantes provenientes de um código genético, de fatores ambientais e históricos que a tornam especial e diferente dos demais (p.37-38).

Considerando as proposições acima, como pensar a educação num mundo regido pelo individualismo, imediatismo e mudanças rápidas? Como reconhecer o valor, "o que é bom" (WERNECK, 2013, p. 38), buscá-lo, apreendê-lo e apossar-se dele, numa sociedade em que, segundo Bauman, "o sucesso da vida dos homens e mulheres pós-modernos depende da velocidade com que conseguem se livrar de hábitos antigos, mais do que a rapidez com que adquirem novos" (2008b, p. 161)?

Segundo o provérbio chinês "Quando planejas por um ano, semeias o grão. Quando planejas por uma década, plantas árvores. Quando planejas por uma vida inteira, formas e educas as pessoas" (PORCHEDDU, 2009, p. 673).

Seguindo a lógica do provérbio chinês, o máximo que a educação conseguiria hoje seria semear grãos. Mas, semear grãos do quê?

\section{Referências}

BAUMAN, Zygmunt. Capitalismo Parasitário e Outros Temas Contemporâneos. Tradução de Eliana Aguiar. Rio de Janeiro: Zahar, 2010.

BAUMAN, Zigmunt. Modernidade Líquida. Tradução de Plínio Dentzein. Rio de Janeiro: Jorge Zahar, 2001.

BAUMAN, Zigmunt. Sobre Educação e Juventude: Conversas com Ricardo Mazzeo. Tradução de Carlos Alberto Medeiros. Rio de Janeiro: Jorge Zahar, 2013.

BAUMAN, Zigmunt. A Sociedade Individualizada: vidas contadas e histórias 
vividas. Tradução de Jorge Gradel. Rio de Janeiro: Jorge Zahar, 2008b.

BAUMAN, Zigmunt. Retrotopia. Tradução de Renato Aguiar. Rio de Janeiro: Zahar, 2017.

BAUMAN, Zigmunt.Vida Para Consumo: a transformação das pessoas em mercadorias. Tradução de Carlos Alberto Medeiros. Rio de Janeiro: Jorge Zahar, 2008a.

CAMBI, Franco. História da pedagogia. São Paulo: Fundação Editora da UNESP (FEU), 1999.

DA POIN, Carmen (Org.). Formas do Vazio: desafios ao sujeito contemporâneo. São Paulo: Via Lettera, 2001.

FLICKINGER, Hans-Georg. A caminho de uma pedagogia hermenêutica. Campinas: Autores Associados, 2010.

GADAMER, Hans-Georg. La educación es educarse. Barcelona: Paidós, 2000b.

GADAMER, Hans-Georg. A filosofia grega e o pensamento moderno. In: ALMEIDA, Custódio Luís Silva de; FLICKINGER, Hans-Georg; ROHDEN, Luiz. Hermenêutica filosófica: nas trilhas de Hans-Georg Gadamer. Porto Alegre: EdiPUCRS, 2000a.

HADOT, Pierre. O que é filosofia antiga?. São Paulo: Edições Loyola, 1999.

JAEGER, WernerWilhelm. Paidéia: a formação do homem grego.4 ed. Tradução deArtur M. Parreira. São Paulo: Martins Fontes, 2003.

LIPOVETSKY, Gilles. A Era do Vazio: ensaios sobre o individualismo contemporâneo. Tradução deTherezinha Monteiro Deutsch.Barueri, São Paulo: Manole, 2005.

MOREIRA, Antonio Flavio Barbosa; CANDAU, Vera Maria. Educação escolar e cultura(s): construindo caminhos. Revista brasileira de educação, n. 23, p. 156-168, 2003. Disponível em: http://www.scielo.br/pdf/rbedu/n23/n23a11. pdf. Acesso em: 19 dez 2018.

PORCHEDDU, Alba. ZygmuntBauman: Entrevista Sobre Educação. Desafios Pedagógicos e Modernidade Líquida. Tradução deNeide Luiza de Rezende e Marcello Bulgarelli. Cad. Pesqui., v.39, n. 137, p.661-684, maio/ago.2009. Disponível em: www.scielo.br/pdf/cp/v39n137a16.pdf. Acessado em 18/juIho/2018. Acesso em: 22 set 2018. 
SILVA, Rafael Bianchi; MENDES, Jéssica Paula Silva; ALVES, Rosieli dos Santos Lopes. O conceito de líquido em Zygmunt Bauman: Contemporaneidade e produção de subjetividade. Athenea digital: revista de pensamiento e investigación social, v. 15, n. 2, p. 0249-264, 2015. Disponível em: http://atheneadigital.net/article/download/v15-n2-silva-mendes-alves/1511-pdf-pt.Acesso em: 22 set 2018.

WERNECK, Vera Rudge. Educação e Sensibilidade: um estudo sobre a teoria dos valores. Rio de Janeiro: Rovelle, 2013.

Data de recebimento: 23.04 .2019

Data de aceite: 17.11.2019 